\title{
Bazı 3-Alkil(Aril)-4-(3-asetoksibenzilidenamino)-4,5-dihidro-1H-1,2,4-triazol-5-on Bileşiklerinin Susuz Ortam Titrasyonları
}

\author{
Özlem GÜRSOY KOL ${ }^{1}$, Zafer OCAK ${ }^{* 2}$, Haydar YÜKSEK ${ }^{1}$ \\ ${ }^{1}$ Kafkas Üniversitesi, Fen-Edebiyat Fakültesi, Kimya Bölümü, 36100, Kars \\ ${ }^{2}$ Kafkas Üniversitesi, Eğitim Fakültesi, Ortaöğretim Fen ve Matematik Alanları Eğitimi Bölümü, 36100, Kars
}

(Alınış / Received: 14.04.2016, Kabul / Accepted: 10.06.2016, Online Yayınlanma/ Published Online: 26.07.2016)

\begin{abstract}
Anahtar Kelimeler
1,2,4-triazol-5-on,

Susuz ortam titrasyonları, $\mathrm{p} K_{\mathrm{a}}$ değerleri,

Yarı nötralizasyon metodu
\end{abstract}

Özet: $\mathrm{Bu}$ çalışmada yedi adet 3-alkil(aril)-4-(3-asetoksibenzilidenamino)-4,5dihidro-1H-1,2,4-triazol-5-on (1) bileșiğinin asitlik özellikleri incelenmiştir. 4,5Dihidro-1H-1,2,4-triazol-5-on türevlerinin sudaki çözünürlükleri çok düşük olduğundan susuz ortam tercih edilmiştir. Bilindiği gibi son yıllarda susuz ortam titrasyonları giderek önem kazanmıştır. Çözücülerin seçiminde farklı çözücü gruplarından olmaları, susuz ortam çözücüsü olarak yaygın kullanımları, dielektrik sabitleri ve otoprotoliz sabitlerinin farklı olması önemli etken olmuştur. Susuz ortamda çözücü olarak amfiprotik nötral çözücülerden izopropil alkol ve tert-butil alkol, dipolar aprotik çözücülerden aseton ve $N, N$ dimetilformamid tercih edilmiştir. Titrant olarak susuz ortam titrasyonlarında geniş kullanım alanı olan tetrabutilamonyum hidroksidin (TBAH) izopropil alkoldeki çözeltisi kullanılmıştır. Asitlik tayininde titrimetrik analiz yöntemlerinde dönüm noktasının belirlenmesi için kullanılan potansiyometrik metot uygulanmıştır. Titrasyon sonucunda elde edilen sonuçlar tablolar ve grafikler halinde verilmiştir. Grafikler incelendiğinde S şeklinde tipik titrasyon eğrileri elde edildiği görülmüştür. Yarı nötralizasyon metoduyla elde edilen veriler ve grafikler kullanılarak bileşiklerin çözücülerdeki asitlik sabitleri hesaplanmıștır. Elde edilen sonuçlara göre bileșiklerin asitlik kuvvetlerinin çözücülerde farklandırıldığı belirlenmiștir. Farklı R grupları içeren 1 tipi bileşiklerin değişik çözücülerdeki asitlik kuvvetleri çözücünün dielektrik sabiti, otoprotoliz sabiti ve seviyeleme-farklandırma etkileri incelenmiştir.

\section{Non-Aqueous Medium Titrations of Some 3-Alkyl(Aryl)-4-(3-acetoxybenzylidenamino)- 4,5-dihydro-1H-1,2,4-triazol-5-ones}

\section{Keywords}

1,2,4-triazol-5-one,

Non-aqueous media,

Titrations,

$\mathrm{p} K_{\mathrm{a}}$ values,

Half-neutralization method

\begin{abstract}
The acidic properties of seven 3-alkyl(aryl)-4-(3-acetoxy benzylidenamino)-4,5-dihydro-1H-1,2,4-triazol-5-ones were investigated. Due to very low solubility of 4,5-dihydro- $1 H$-1,2,4-triazol-5-one derivatives in water, nonaqueous media were used. The titrations in non-aqueous media have increasingly utilized in recent years. In determining the solvents used, their belonging to different solvent groups, wide use as solvent in non-aqueous investigations and having different autoprotolysis constants were considered. In non-qaueous medium, isopropyl alcohol and tert-butyl alcohol among the amphiprotic type, and aceton and $N, N$-dimethylformamide among the dipolar aprotic type were preferred as solvent. The results obtained from the titrations are presented in tables and graphs. Typical S-shaped titration curves are observed in the graphs. The acidity constants of the compounds in the solvents chosen were calculated using the graphs and the data obtained with half-neutralization method. The acidity strength of the compounds was observed to differ from the information obtained. The acidity strength of $\mathbf{1}$ type compounds with varying $\mathrm{R}$ groups in different solvents, dielectric constant of the solvents, autoprotolysis constant and leveling-differentiation effects were investigated.
\end{abstract}




\section{Giriş}

Temelde ideal bir çözücü yoktur. Su ideal çözücü özelliklerine oldukça yakın olduğundan uygulamaların büyük bir bölümünde çözücü olarak kullanılır. Su Asit-baz titrasyonlarının meydana geldiği olağanüstü çok yönlü bir çözücü olmasına rağmen susuz ortam çözücüsü gerekli olabildiği yada tercih edilebildiği durumlar vardır. Örneğin analitin suda çözünmediği ve nötralleşme reaksiyonunun suda yeterince tamamlanmadığ d durumlar vardır. Eksiksiz nötralleşme reaksiyonu kısmen analitin asit baz kuvvetine bağlıdır. Fakat Bronsted ve Lowry asitlik ve bazlığın çözücüye bağlı olduğunu açıkca gözlemlemiştir[1]. Çözücü ve yapısal etki bir molekülün asitliği ya da bazlığına etki eden iki ana faktör olduğu iyi bilinir. Moleküllerin çoğunda her iki etki oluşmasına rağmen daha çok yapı etkisi vardır. Bazen yapı ve çözücülerin etkisini farklandırmak oldukça güçtür[2,3]. Bazen suda titre etmek için çok zayıf bir asit gözlemlenen asitliği daha büyük olan susuz ortam çözücülerinde titre edilebilir. Örnek olarak sudaki çözünürlüğü çok az olan triazol bileşiklerinin asitliklerini sulu ortamda tespit etmek güçtür. $\mathrm{Bu}$ nedenle susuz ortam çözücüleri tercih edilir.

Susuz ortam reaksiyonları saf su hariç diğer çözücüler içinde cereyan eden reaksiyonlardır. Organik maddeler gibi suda çözünmeyen maddelerin bazı özelliklerinin araştırılması amacıyla susuz çözücülere (organik çözücüler) ihtiyaç duyulmuştur. Suda çözünmeyen on binlerce organik maddeyi bu çözücülerde çözmek ve titre etmek mümkün olmuştur. Organik çözücüler hidrojen bağı akseptörü veya donörü olmalarına, ortaklanmamış elektron çifti akseptörü veya donörü olmalarına, dipol momentlerine ve dielektrik sabitlerine göre çeşitli gruplara ayrlabilir. Ancak bunlar arasında kesin sınırlar yoktur. Şöyle ki elektron çifti donörü veya akseptörü olan çözücüler, hidrojen bağı donörü veya akseptörü olan çözücülerden farklı yapı ve özelliklerde çözücüler değildirler. Organik çözücüler hidrojen bağı söz konusu olunca nötral çözücüler, protojenik çözücüler ve protofilik çözücüler olarak üç gruba ayrılır. Daha çok hidrojen bağı akseptörü olan çözücülere dipolar aprotik çözücüler denir. Dipolar aprotik çözücüler Protofilik ve Protofobik çözücüler olarak ikiye ayrılır. Hidrojen bağı donörü veya akseptörü olmayan çözücülere ise inert çözücüler denir[4,5].

Susuz ortam çözücülerindeki asit-baz dengeleri sudakilerden önemli derecede daha karmaşıtktır. Dolayısıyla birçok önemli denge sabiti bilinmez. Sonuç olarak teorik titrasyon eğrilerini oluşturmak için gereken verileri hesaplamak zordur [2-4]. Çözeltiler içindeki asit-baz dengelerini daha iyi anlamak için genellikle polar aprotik çözücüler kullanılır; bu polar aprotik çözücüler çok zayıf olmasına rağmen yine de ölçülebilir amfiprotik özellikler gösterir. Kuvvetli farklandırma özellikleri sebebiyle suda gözlenemeyen bazı özellikler polar aprotik çözücülerde gözlenebilir [6].

Yapılan bu çalışmada sentezlenen 3-alkil(aril)-4-(3asetoksibenzilidenamino)-4,5-dihidro- $1 H-1,2,4$ -

triazol-5-on bileşiklerinin asitlik özellikleri incelenmiştir. Çalışmada amfiprotik ve dipolaraprotik çözücülerde TBAH'in izopropil alkoldeki $0.05 \mathrm{~N}$ çözeltisi ile titre edilmiştir. Dönüm noktası potansiyometrik titrasyon metodu ile belirlenmiştir [7-9]. Her bir ortam için asitlikleri yarı nötralizasyon yöntemiyle belirlenmiştir. Ayrıca, bulunan sonuçlar çözücü etkisi, substituent etkisi, dielektrik sabiti etkisi ve her bir çözücüdeki asitlik kuvvetleri etkisi yönünden incelenmiştir.

\section{Materyal ve Metot}

\section{1. Çalışılan maddeler}

Çalışmada 3-alkil(aril)-4-(3-asetoksibenzilidenamino)-4,5-dihidro-1H-1,2,4-triazol-5-on türevi yedi bileşik kullanılmıştır. Bu heterosiklik bileșikler "Şekil 1." Kaynak $[10,11]$ uyarınca sentezlenmiştir.
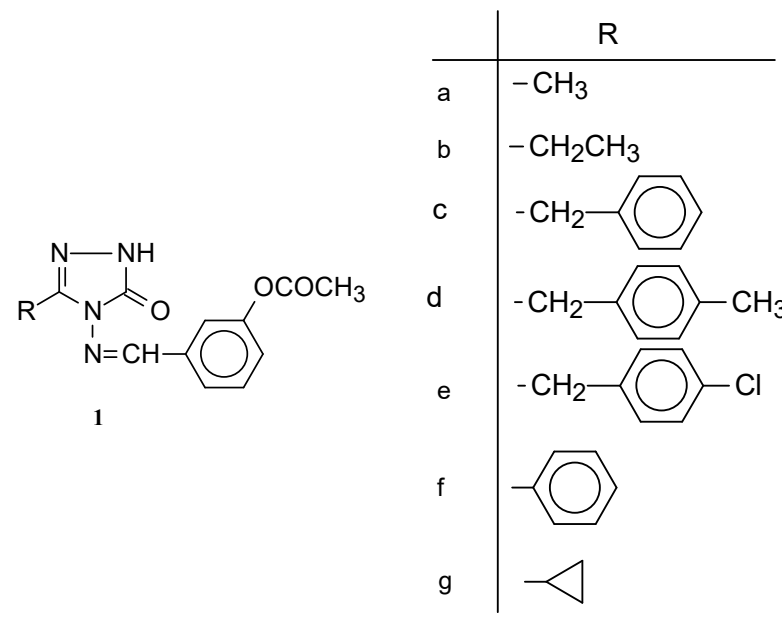

Şekil 1. 3-Alkil(Aril)-4-(3-asetoksibenziliden-amino)-4,5dihidro-1H-1,2,4-triazol-5-on Bileșikleri

\section{2. Çözücüler}

3-Alkil(Aril)-4-(3-asetoksibenzilidenamino)-4,5 dihidro-1H-1,2,4-triazol-5-on bileșiklerinin asitlik sabitlerinin tayininde susuz ortam çözücülerinden izopropil alkol, tert-butil alkol, aseton ve $N, N$ dimetilformamid (DMF) tercih edilmiștir. Yapılan tercihte titrant ve asitlerin çözücü içerisinde iyi çözünmeleri, çözücülerin sağladığı geniş potansiyel aralığı, atmosfer şartlarında çalışma imkânı etkili olmuştur. Titrant olarak (TBAH) tetrabutilamonyum hidroksit'in izopropil alkoldeki çözeltisi kullanılmıştır. Çözücüler izopropil alkol, aseton 
$N, N$-dimetilformamid ve tert-butil alkol Merck firmasından temin edilmiştir.

\subsection{Titrantlar}

Asitlerin titrasyonunda geniş ölçüde kullanılan bazik bir titrant olan TBAH kullanılmıştır. Asitlerin titrasyonunda titrant olarak tetrabutilamonyum hidroksit'in (TBAH) izopropil alkoldeki standart 0.1 N'lik çözeltisi seyreltilerek 0.05 N'lik çözeltisi kullanılmıştır. Çözelti Merck firmasından alınmıştır.

\section{4. Cihazlar}

Yapılan çalışmada Jenway 3040 Model Ion Analyser kullanılmıştır. $\mathrm{pH}$ ölçümlerinde \pm 0.001 hassasiyette \pm 0.005 kesinlikte, $\mathrm{mV}$ ölçümünde $\pm 0.1^{\prime}$ 'lik hassasiyette ve \pm 0.2 kesinlikteki Ion Analyser tercih edilmiştir. Elektrot olarak sağladığı büyük avantajlar nedeniyle ingold kombine $\mathrm{pH}$ elektrodu tercih edilmiștir. Titrasyonlarda $50 \mu \mathrm{L}$ lik mikropipet kullanılmıştır.

\subsection{Hazırlanan çözeltiler}

4,5-Dihidro-1H-1,2,4-triazol-5-on türevlerinin aseton, tert-butil alkol $N, N$-dimetilformamid ve izopropil alkoldeki $10^{-3}$ M 100 mL'lik çözeltileri hazırlanmıştır. Titrant olarak kullanılan TBAH'ın izopropil alkoldeki 0.1 N'lik standart çözeltisinden seyreltilerek $0.05 \mathrm{~N}$ 250 mL'lik çözeltisi hazırlanmıștır.

\subsection{Yöntem}

Potansiyometrik titrasyon için gerekli çalışma düzeneği hazırlanmıştır. Tampon tabletler yardımıyla pH'sı $7.00 \pm 0.02\left(25^{\circ} \mathrm{C}\right)$ ve $10.00 \pm 0.05\left(25^{\circ} \mathrm{C}\right)$ olan iki adet tampon çözelti hazırlanmıştır. pH metre standart tamponlar yardımıyla kalibre edilmiştir. Bütün bu çalışmalar $25^{\circ} \mathrm{C}$ 'de yapılmıştır. 3,3Alkil(Aril)-4- Benzilidenamino- 4,5 Dihidro-1H -1,2,4Triazol-5-On türevlerinin hazırlanan $10^{-3} \quad \mathrm{M}^{\prime} \mathrm{llk}$ çözeltisinden $17 \mathrm{~mL}$ 'lik bir beher içine alınmıştır. Çözelti mağnetik karıştırıcıyla karıștırılarak homojen hale getirilmiştir. Mikropipetten karışmakta olan asit çözeltisine her defasında 0.05 mL 0.05 N'lik TBAH'ın izopropil alkol çözeltisi ilâve edilmiştir. Cihazdan okunan $\mathrm{pH}$ ve $\mathrm{mV}$ değerleri sabit kalıncaya kadar titrasyona devam edilmiştir. $\mathrm{pH}$ metreden okunan $\mathrm{mV}$ değerleri titrant hacmine $(\mathrm{mL})$ karşı grafiğe geçirilmiştir.

\subsection{Asitlik sabitlerinin tayini}

\subsubsection{Yarı nötralizasyon metodu}

Titrasyonlar sonucunda titrant hacmine karşllı olan $\mathrm{pH}$ ve $\mathrm{mV}$ değerleri okunarak bu değerlere göre titrasyon grafiği çizilmiştir. Birinci ve ikinci türev grafiklerinden yararlanılarak dönüm noktaları bulunmuştur.
Zayıf asit ve bazların yarı nötralizasyon noktalarındaki $\mathrm{pH}$ değeri $\mathrm{p} K_{\mathrm{a}}$ değerlerine eşit olduğu için $\mathrm{pH}$ değerleri $\mathrm{p} K_{\mathrm{a}}$ değerleri olarak alınmıştır. Çünkü zayıf asit ve onun tuzu bir tampon çözelti oluşturur. Tampon çözeltide:

$$
\mathrm{pH}=\mathrm{p} K_{\mathrm{a}}+\log \frac{\left[\mathrm{A}^{-}\right]}{[\mathrm{HA}]}
$$

eşitliğinden yarı nötralizasyonda,

$$
\left[\mathrm{A}^{-}\right]=[\mathrm{HA}]
$$

olduğundan $\mathrm{pH}=\mathrm{p} K_{\mathrm{a}}$ elde edilir $[12,13]$.

\section{Bulgular}

3-Alkil(Aril)-4-(3-asetoksibenzilidenamino)-4,5dihidro-1H-1,2,4-triazol-5-on bileşiklerinin aseton, $\mathrm{N}, \mathrm{N}$-dimetilformamid, tert-butil alkol ve, izopropil alkol çözücülerindeki $10^{-3} \mathrm{M}$ 'lık çözeltisinin $0.05 \mathrm{~N}$ TBAH çözeltisi ile titrasyonu sonucu elde edilen değerler kullanılarak TBAH hacmine karșı mV olarak grafikleri çizilmiştir. Bileşiklerin tert-butil alkol, $\mathrm{N}, \mathrm{N}$-dimetilformamid, aseton ve izopropil alkoldeki titrasyon grafikleri “Şekil 2-5."de verilmiştir.

$\mathrm{Bu}$ grafikler Excel programında çizilmiştir. Bileşiklerin asitlik sabitleri Yarı nötralizasyon metoduna göre hesaplanmıştır [14-17]. Elde edilen sonuçlar "Tablo 1." de verilmiştir.

Tablo 1. 3-Alkil(Aril)-4-(3-asetoksibenzilidenamino)-4,5dihidro-1H-1,2,4-triazol-5-on bileşiklerinin izopropil alkol, tert-butil alkol, aseton, N,N-dimetilformamid çözücülerindeki asitlik sabitleri

\begin{tabular}{ccccc}
\hline BİLEŞiK & DMF & Aseton & $\begin{array}{c}\text { tert-Butil } \\
\text { Alkol }\end{array}$ & $\begin{array}{c}\text { izopropil } \\
\text { Alkol }\end{array}$ \\
a & 16,75 & 15,80 & 15,29 & 12,89 \\
b & 16,06 & 16,20 & 15,50 & 13,23 \\
$\mathbf{c}$ & 16,48 & 15,46 & 14,70 & 12,09 \\
$\mathbf{d}$ & 15,84 & 15,17 & 15,10 & 13,67 \\
$\mathbf{e}$ & 15,90 & 15,78 & 15,11 & 13,03 \\
$\mathbf{f}$ & 16,10 & 14,40 & 14,42 & 12,80 \\
$\mathbf{g}$ & 16,51 & 15,85 & 14,44 & 14,11 \\
\hline
\end{tabular}

\section{Tartışma ve Sonuç}

4,5-dihidro-1H-1,2,4-triazol-5-on halka sisteminde N$\mathrm{H}$ protonunun zayıf asidik özellik gösterdiği bilinmektedir[18-22]. N-H protonunun asidik özellik göstermesi aşağıdaki gibi açıklanabilir:

4,5-dihidro-1H-1,2,4-triazol-5-on halkasındaki $\mathrm{N}-\mathrm{H}$ hidrojeni proton halinde ayrıldığında oluşan anyon rezonans ile kararlılık kazandığından, başka bir deyişle hidrojen proton halinde ayrıldığında geride kalan elektron çifti ikinci elektronegatif atom olan oksijeni de içine alacak şekilde delokalize olduğundan ve barındırılması kolay olduğundan denge sağa kayar; dolayısıyla da asitlik artar. 


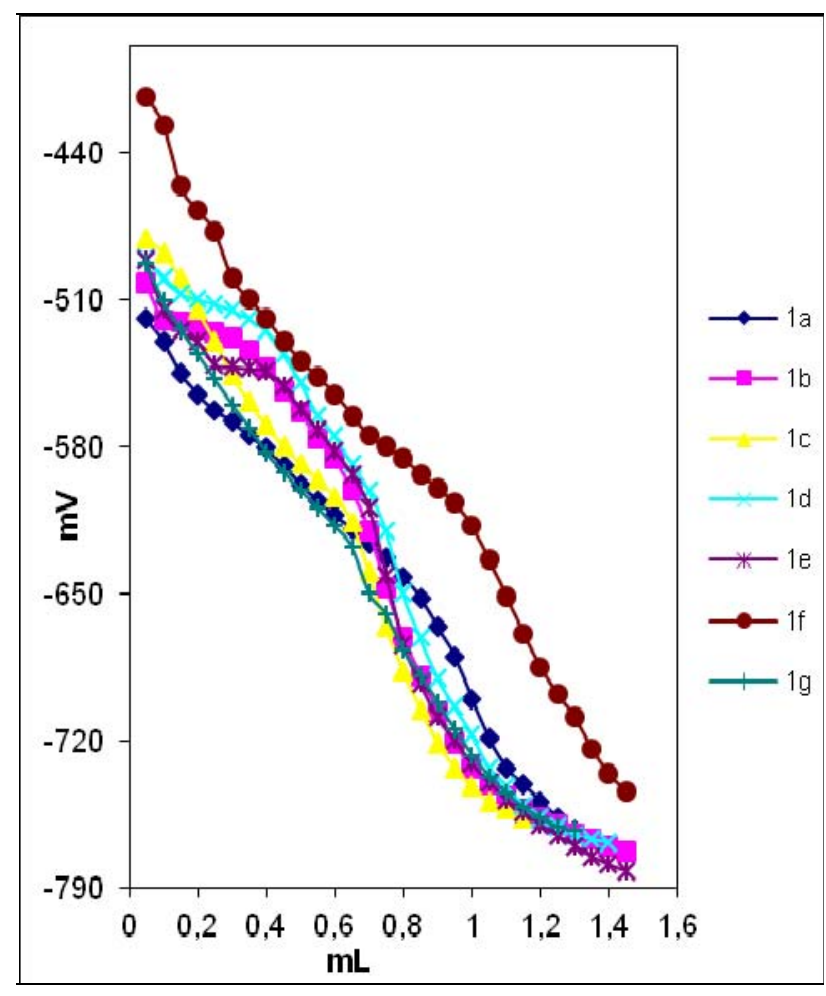

Şekil 2. 3-Alkil(Aril)-4-(3-asetoksibenziliden-amino)-4,5dihidro-1H-1,2,4-triazol-5-on bileșiklerinin $\quad \mathrm{N}, \mathrm{N}$ dimetilformamiddeki $10^{-3}$ M'lık çözeltilerinin $0.05 \mathrm{~N}$ TBAH ile titrasyon grafikleri

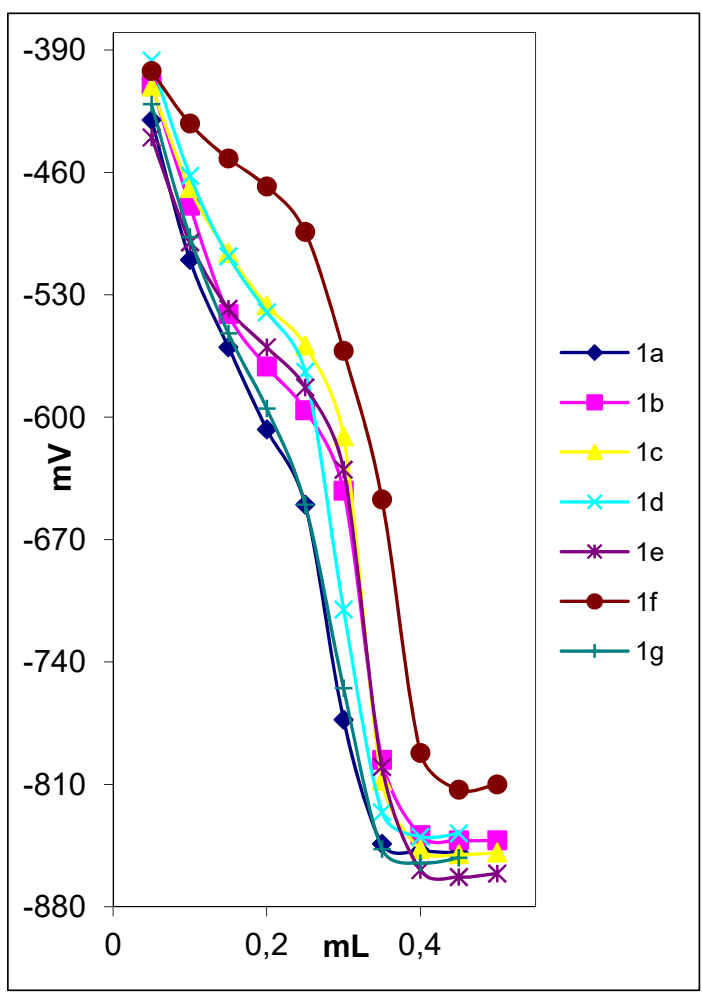

Şekil 3. 3-Alkil(Aril)-4-(3-asetoksibenziliden-amino)-4,5dihidro- $1 H-1,2,4$-triazol-5-on bileşiklerinin asetondaki $10^{-3} \mathrm{M}^{\prime}$ llk çözeltilerinin $0.05 \mathrm{~N}$ TBAH ile titrasyon grafikleri

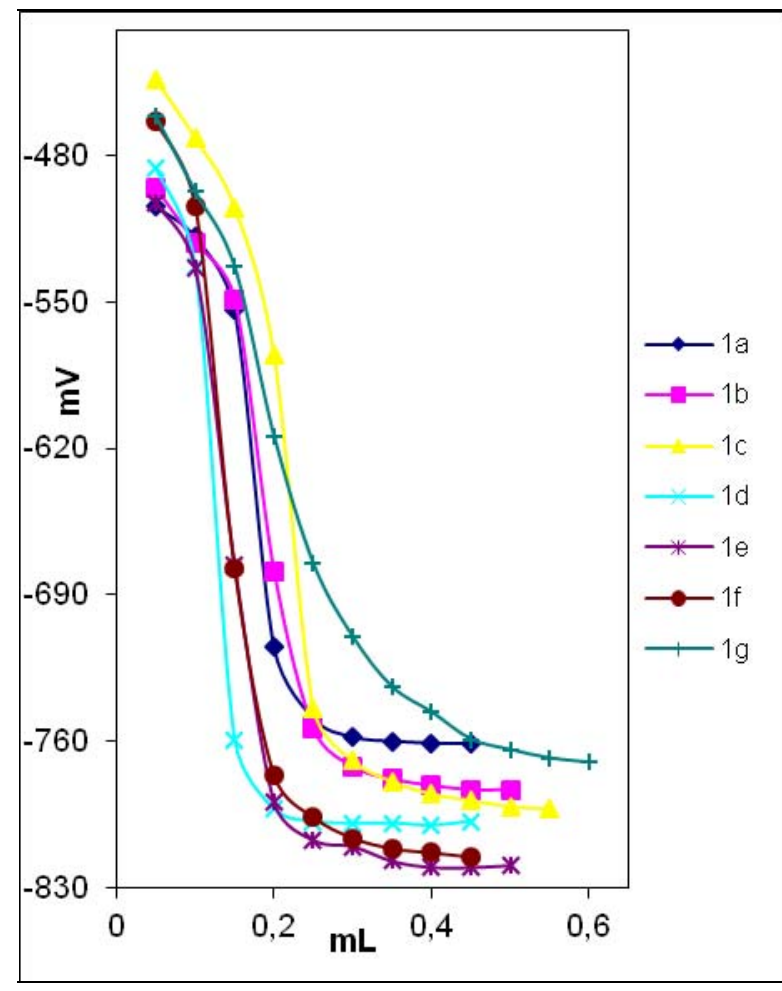

Şekil 4. 3-Alkil(Aril)-4-(3-asetoksibenziliden-amino)-4,5dihidro-1H-1,2,4-triazol-5-on bileșiklerinin tert-butil alkoldeki $10^{-3}$ M'lık çözeltilerinin $0.05 \mathrm{~N}$ TBAH ile titrasyon grafikleri

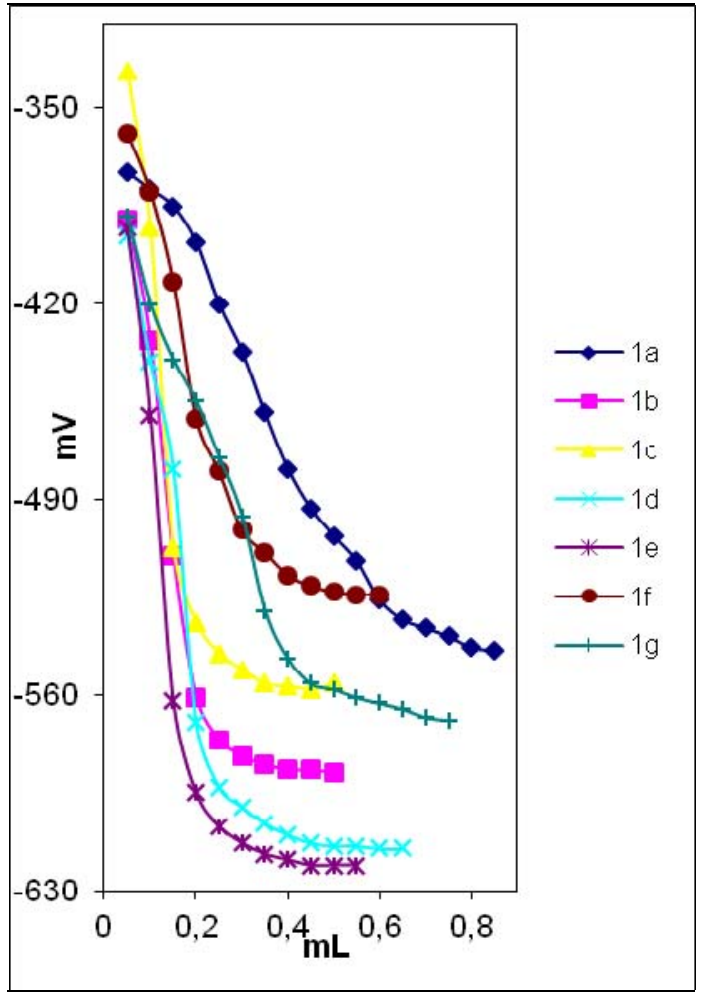

Şekil 5. 3-Alkil(Aril)-4-(3-asetoksibenziliden-amino)-4,5dihidro-1H-1,2,4-triazol-5-on bileșiklerinin izopropil alkoldeki $10^{-3}$ M'lık çözeltilerinin $0.05 \mathrm{~N}$ TBAH ile titrasyon grafikleri 


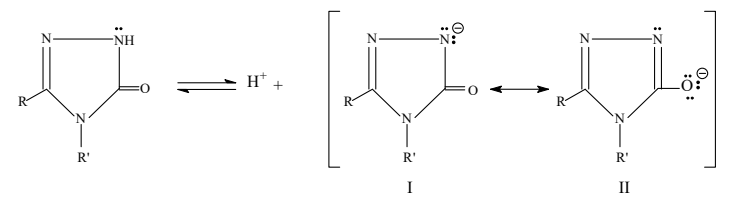

Sekil 6. 4,5-Dihidro-1H-1,2,4-triazol-5-on halkasındaki N-H hidrojeni proton halinde ayrıldığında oluşan anyondaki rezonans

I ve II rezonans strüktürlerinin rezonans hibridi III olup, negatif yükün elektronegatif azot ve oksijen atomlarını içine alacak şekilde delokalize olduğunu göstermektedir.

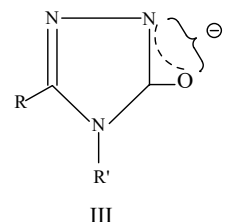

Şekil 7. I ve II rezonans strüktürlerinin rezonans hibridi

Hesaplanan $\mathrm{p} K_{\mathrm{a}}$ değerleri çözücülerin dielektrik sabiti ve otoprotoliz sabitine karșı grafiği çizilmiștir "Şekil 8.". Çözücülerin dilelektrik sabitine göre bileşiklerin asitlik kuvvetleri, otoprotoliz sabitlerine göre çalışılan bileşikleri seviyeleme ve farklandırma etkileri değerlendirilmiştir.

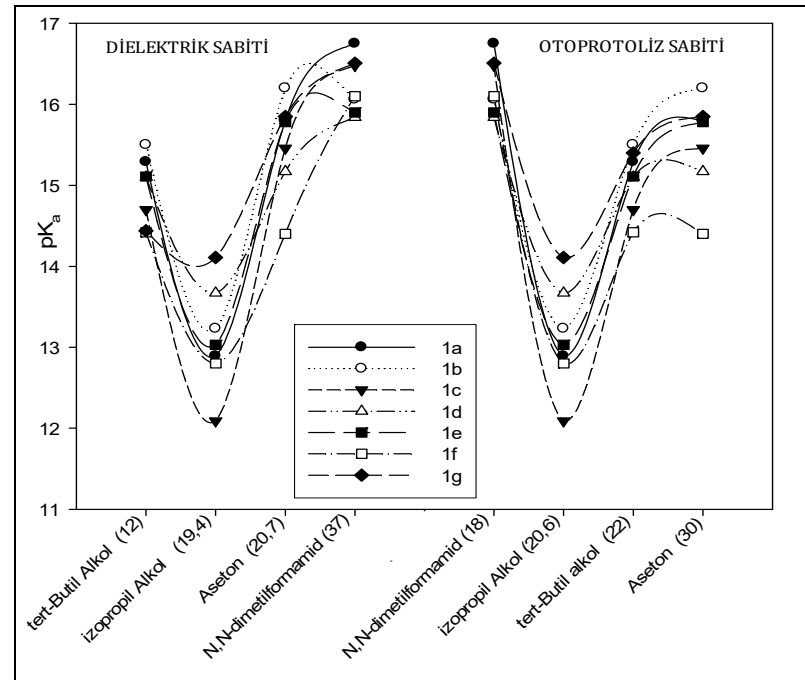

Şekil 8. 1 tipi bileşiklerin $\mathrm{p} K_{\mathrm{a}}$ değerlerinin dielektrik ve otoprotoliz sabitlerine göre değişim grafikleri

Dilelektrik sabitine göre incelendiğinde teorik olarak asitlik sıralaması, dielektrik sabitinin artmasıly asitlik sabiti artmıştır. Bu sonuca göre asitlik sabiti artışı tert-butil alkol < izopropil alkol < aseton $<N, N$ dimetil formamid şeklinde gerçekleşmiştir.

Amfiprotik çözücüler olan izopropil alkol ve tert-butil alkol incelendiğinde literatüre uygun olarak tüm bileşikler izopropil alkolde daha asidik özellik gösterdiği tespit edilmiştir.

Dipolar aprotik çözücüler olan aseton ve $N, N$ dimetilformamid incelendiğinde $1 \mathrm{~b}$ bileşiğinin teorik siralamaya uygun olarak $\mathrm{N}, \mathrm{N}$-dimetilformamid'de daha asidik özellik gösterirken diğer bileşikler aseton ortamında daha asidik olarak tespit edilmiştir. $\mathrm{Bu}$ durum aşağıdaki gibi açılklanabilir.

Dipolar aprotik çözücüler liyonyum iyonu verdikleri halde liyat iyonu vermezler. Moleküler asit HA ve çözücü S olduğunda protofilik $(N, N$-dimetilformamid gibi) çözücülerde denge,

$\mathrm{HA}+\mathrm{S} \rightleftharpoons \mathrm{S} \cdot \cdots \cdot \mathrm{HA} \rightleftharpoons \mathrm{SH}^{+} \mathrm{A}^{-} \rightleftharpoons \mathrm{SH}^{+}+\mathrm{A}^{-}$

şeklindedir. (5) numaralı dengelerde protofilik çözücülerde birinci ve ikinci dengeler büyük oranda gerçekleşirken üçüncü denge çok düşük oranda sağa kayar. Üçüncü dengedeki serbest $\mathrm{SH}^{+}$ortamda bulunabilecek en kuvvetli asittir ve titrantla doğrudan reaksiyona girebilir. Ancak çözücü protofobik (aseton gibi) ise (5) dengesi çok daha düșük oranda sağa kayar. Üçüncü denge ise eser oranda meydana gelir. Böyle protofobik çözücüde meydana gelen $\mathrm{SH}^{+}$iyonu, protofilik çözücüde meydana gelenden çok daha kuvvetli asittir.

Otoprotoliz sabitine göre incelendiğinde izopropil alkol ve $\mathrm{N}, \mathrm{N}$-dimetilformamid ortamında bileşikler zayıf asidik olduğu görülmüştür. Aseton ortamında çalışılan 1a, 1c, 1d, 1e ve 1g bileşikleri nötral, 1b bileşiği zayıf asidik, 1f bileşiği ise asidik karakterde iken, tert-butil alkol ortamında bileşikler zayıf asidik özellikte olduğu belirlenmiştir.

Yapılan çalışma sonucunda kullanılan çözücülerde bileşiklerin farklandırıldığı belirlenmiştir. Ayrıca C-3'e bağlı substituentlerin (molekül yapısının) asitlik üzerine etkisinin anlamlı olmadığ sonucuna varılmıştır.

\section{Teşekkür}

$\mathrm{Bu}$ çalışma 1071T247 nolu proje ile TÜBİTAK tarafından desteklenmiştir

\section{Kaynakça}

[1] Hargis, L.G. 1988. Analytical Chemistry Principles and Techniques. Prentice-Hall. Inch, New Jersey, 672s.

[2] Gündüz, T., Gündüz, N., Kıllı̧, E., Gürkan, P. 1987. Part VI. Effects of Substituents on Basicity or Acidity of N-Salicylidene-2-Hydroxyaniline, Analyst, 112(1987), 1057-1061.

[3] Gündüz, T., Kılıç, E., Ertüzün, V., Çetinel, G. 1986. Part V. Acid-Base Behaviour Of Substituted 2-Amino-3-Cyanofurans,2-Amino-3-Cyano thiophenes and 2-Amino-3-Cyanopyrrole And Their Schiff Bases with Salicylaldehyde and 2Hydroxy-1-Naphthaldehyde, Analyst, 111(1986) 1439-1442. 
[4] Aksu, H. 2005. Bazl 3-Substutie-4-(PNitrobenzoilamino)-4,5-Dihidro-1H-1,2,4Triazol-5-On Türevlerinin Asitlik Kuvvetlerinin Tayini, Kafkas Üniversitesi, Fen Bilimleri Enstitüsü, Yüksek Lisans Tezi, 66s, Kars

[5] Christion, G.D. 1977. Analytical Chemistry. Second Edition, John Wiey and Sons Inc., New York, 648s.

[6] Chmurzynski, L., Kaczmarczyk, E., Nesterowicz, Wawrzyniak, G., Warnke, Z. 1996. A Potentiometric Study on Proton-Transfer Equilibria and Cationic Conjugated in Pyridine N-Oxide Systems in Acetone and Methanol, Australian Journal of Chemistry, 49(1996) 931942.

[7] Farkas, Z., Posa, M., Tepavcevic, V. 2014. Determination of pKa Values of Oxocholanoic Acids by Potentiometric Titration, J Surfact Deterg, 17 (2014), 609-614.

[8] Sahoo, P., Malathia, N., Ananthanarayanan, R., Praveen, K., Murali, N. 2011. A novel approach for high precision rapid potentiometric titrations: Application to hydrazine assay, Review of Scientific Instruments, 82(2011), 114102-1/9.

[9] Lakubowska, M., Bas, B., Niewiara, E., Reczynski, W., Kubiak, W.W. 2009. Potentiometric Titration of Industrial Samples-End-point Detection by Means of Wavelets, AIP Conference Proceedings, 1148(2009), 613-616.

[10] Gürsoy-Kol, Ö., 2008. Bazı 4,5-Dihidro-1H-1,2,4Triazol-5-on Türevlerinin Sentezi, Yapılarının Aydınlatılması, Antioksidan ve Asitlik Özelliklerinin İncelenmesi, Kafkas Üniversitesi, Fen Bilimleri Enstitüsü, Doktora Tezi, 393s, Kars

[11] Gürsoy-Kol, Ö., Yüksek., H., Alkan., M, 2014. Bazı yeni 3-alkil(aril)-4-benzilidenamino-4,5dihidro-1H-1,2,4-triazol-5-on bileşiklerinin sentezi ve antioksidan özelliklerinin incelenmesi, Caucasian Journal of Science, 1(2014), 89-97.

[12] Kılıç, E., Köseoğlu, F. ed. 1999. Analitik Kimya Temelleri. Bilim Yayıncllık. Ankara, 496s.

[13] Gündüz, T. 2002. İnstrümental Analiz. 6. Baskı, Genişletilmiş ve Gözden Geçirilmiş, Gazi Kitabevi. Ankara, 1357s.

[14] İslamoğlu F., Yüksek H., Özdemir M. 2011. Acidic Properties of Some 1,2,4- Triazole Derivates in Non-aqueous Media, Der Chemica Sinica, 2(3)(2011), 117-124.

[15] Kurtoğlu, M., Birbiçer, N., Kimyonsen, Ü., Serin, S. 1999. Determination of pKa Values of Some Azo Dyes in Acetonitrile with perchloric Acid, Dyes and Pigments., 41(1999), 143-147.
[16] Karaböcek, S., Dalman, Ö., Nohut, S., Tüfekçi, M., Sancak, K., Güner, S. 1998. Determination of Relative Acidities of Some $\alpha, \omega$-bis(3-alkyl(aryl)4,5-dihydro-1H-1,2,4-triazol-5-on-4-yl)Alkanes, J. Pharmaceutical and Biomedical Analysis., 17(1998), 375-378.

[17] Gündüz, N., Gündüz, T., Havyalı, M. 1999. Titrations in Non-Aqueous Media: Potentiometric Investigation of Symmetrical and Unsymetrical Tetra-Aryl Porphyrins With 4Nitrophenyl and 4-Aminophenyl Substituents in Nitrobenzene Solvent, Talanta, 48(1999), 71-79.

[18] Alkan. M., Gürbüz. A., Yüksek., H., Gürsoy-Kol, Ö., Ocak, Z. 2014. Synthesis and non-aqueous medium titrations of some new 3-alkyl(aryl)-4[2-(4-methoxybenzoxy)-3-methoxy]benzylidenamino-4,5-dihydro-1H-1,2,4-triazol5-ones, Caucasian Journal of Science, 1(2014), 138-147.

[19] Aktaş-Yokuş, Ö., Yüksek, H., Gürsoy-Kol, Ö., Karaoğlu. A. Ş. 2015. Synthesis and biological evaluation of new 1,2,4-triazole derivatives with their potentiometric titrations, Med. Chem. Res, 24(2015), 2813-2824.

[20] Yüksek, H., Üçüncü, O., Alkan, M., Ocak, Z., Bahçeci, Ş., 2005, Non-Aqueous Medium Titrations of Some New 4-Benzylidenamino-4,5dihydro-1H-1,2,4-triazol-5-one Derivatives, Molecules, 10 (2005), 961-970.

[21] Yüksek, H., Ocak, Z., Manap, S., Şahin, N., Ağırbaș, H. 2009. Determination of $\mathrm{p} k_{\mathrm{a}}$ Values Some 4-[4(4-Nitrobenzoxy)-Benzylidenamino-4,5Dihydro-1 $H-1,2,4-T r i a z o l-5-o n e$ Derivatives In Non-Aqueous Solvents, $5^{\text {th }}$ Black Sea Basin Conferenca on Analaytical Chemistry, 23-26 Eylül. Ordu, Book of Abstracts, 118.

[22] Arslantaş, A., Yüksek, H., Gürsoy-Kol, Ö., Ocak, Z., Tomruk, Z., Calapoğlu, M. 2012. Synthesis, determination of pK(a) values and GIAO NMR calculations of some new 3-alkyl-4-(pmethoxybenzoylamino)-4,5-dihydro-1H-1,2,4triazol-5-ones, Asian J. Chem. 24, (2012), 33273334. 